\title{
Development of Porous Titanium Sheet with High Porosity and Good Mechanical Properties
}

\author{
Yasuhiko Goto, Yosuke Inoue, Hideki Fujii and Matsuhide Horikawa \\ TOHO TITANIUM CO., LTD, Chigasaki-City Kanagawa, Japan
}

\begin{abstract}
$\underline{\text { Abstract }}$
To respond to the requirements for porous Ti sheet with the balanced properties of high porosity and good mechanical properties, and to optimize the manufacturing conditions of the simple powder-filling plus sintering process, effects of sintering temperatures on density and bending strength in porous Ti sheet were investigated. The optimum sintering condition was $900-950{ }^{\circ} \mathrm{C}$ for $1 \mathrm{~h}$ to obtain porous Ti sheet with the balanced density ratio (around $40 \%$ ) and high bending strength. The polyhedron shape of HDH powders contributed to those balanced properties, in which localized sintering raised bending strength with keeping high porosity (low density). Using the optimum manufacturing conditions, large sized porous Ti sheet of $400 \times 800 \times 0.5 \mathrm{~mm}$ was successfully manufactured.
\end{abstract}

\section{Introduction}

With expanding the use of functional corrosive fluids such as low $\mathrm{pH}$ electrolytes in various kinds of batteries, requirements for thin gauge porous materials with high porosity and high corrosion resistance are rapidly increasing. Although various porous titanium products have been studied so far through various manufacturing processes to apply for various applications including implants ${ }^{(1-2)}$, they are limited to relatively bulky products of $1 \mathrm{~mm}$ or more in thickness. Toho Titanium has tried to manufacture three kinds of porous titanium sheets of $1 \mathrm{~mm}$ or thinner in thickness ${ }^{(3)}$. One is manufactured by sintering Ti powders which are loosely filled in the shallow flat depressed area of $1 \mathrm{~mm}$ or less in depth, another is manufactured by sintering fine Ti powders which are loosely filled in polymer binder in the form of thin sheet of $0.5 \mathrm{~mm}$ or less in thickness, which is fabricated by utilizing screen printing technique, and the other is manufactured by sintering Ti short fibers. The last one is most porous, whose porosity is more than $70 \%$, and the second one is thinnest among the three, resulting in high flexibility as shown in Fig.1. However, the first one is most simple in manufacturing process, in which simple sintering of loosely spread Ti powders, and expected to be manufactured with lowest cost.

In this respect, it is quite beneficial from industrial viewpoint to optimize the properties of the first one within the basic simple processing conditions. Based on that background, effects of sintering conditions and grain size on porosity (density) and mechanical properties were investigated in the simple sintering of loosely spread Ti powders made by hydrogenation and de-hydrogenation process, and the optimum condition balancing those two properties was discussed. 


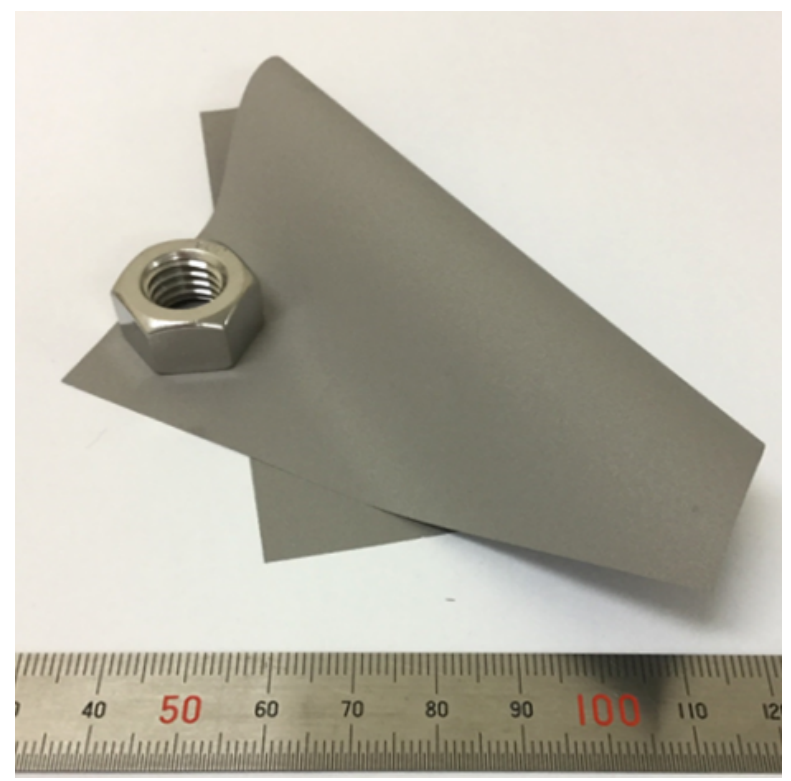

Fig. 1 Porous titanium sheet of $0.04 \mathrm{~mm}$ in thickness manufactured using screen printing technique. It is so flexible to be bent like paper (3).

\section{Experimental procedures}

\section{2-1.Preparation of specimens}

Two kind of Ti powders manufactured by hydrogenation and de-hydrogenation $(\mathrm{HDH})$ process were used. Particle size and $\mathrm{O}$ content of the first powders was as follows : D50 was $69 \mu \mathrm{m}$, sieved powder size was between 45 and $150 \mu \mathrm{m}$, O content was 0.11 mass $\%$ (powder A). SEM image of the powders is shown in Fig.2. Those of the second powders was as follows : D50 was $62 \mu \mathrm{m}$, sieved powder size was between 10 and $150 \mu \mathrm{m}, \mathrm{O}$ content was 0.15 mass \% (powder B). The second powders contained finer Ti powders between 10 and $45 \mu \mathrm{m}$, which raised $\mathrm{O}$ content slightly.

Ti powders were overfilled in a depressed area of $60 \times 15 \mathrm{~mm}$ in area and of $0.5 \mathrm{~mm}$ in depth in a flat surface of a horizontally placed ceramic tool called "setter", and leveled off by sliding a ceramic bar having square cross section. Levelling process was repeated many times until the surface of the powder filled area was fully flattened and the depth of the powders filled in the depressed area became uniform, $0.5 \mathrm{~mm}$. Then, the ceramic setter, in which Ti powders were set in the depressed area, was installed in a vacuum furnace, and sintered in vacuum. Heat treatment pattern for sintering was heating to prescribed temperature $\left(800\right.$ to $\left.950{ }^{\circ} \mathrm{C}\right)$ for $1 \mathrm{~h}$, holding for $1 \mathrm{~h}$ and cooling to room temperature by furnace cooling. Sintered Ti was separated from the setter taken out of the furnace and subject to evaluation. 


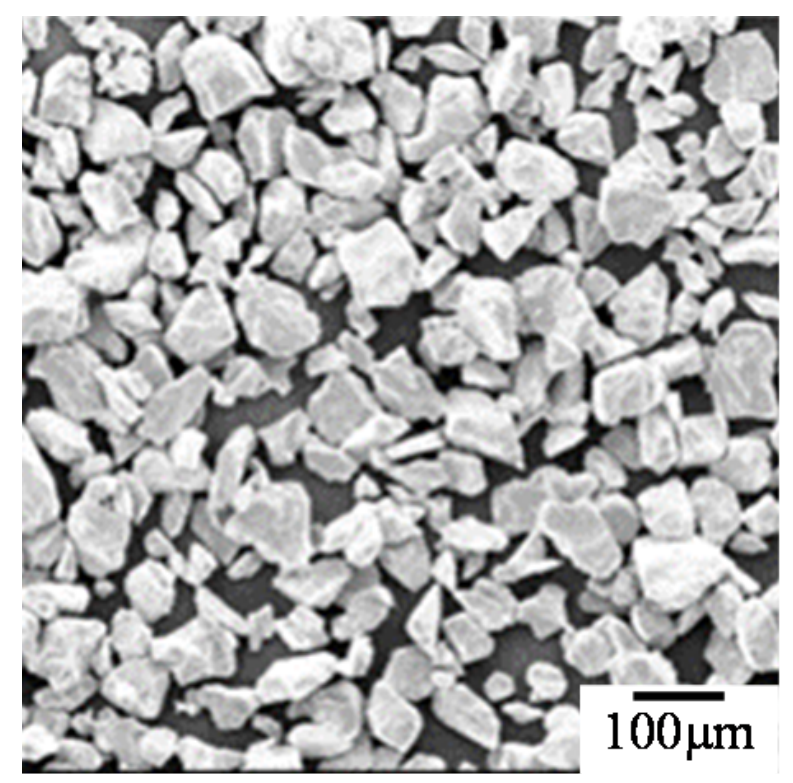

Fig.2 SEM image of hydrogenated and de-hydrogenated (HDH) powders used (powder A).

\section{2-2.Evaluation}

O content measurement, density measurement, surface analyses by SEM, microstructure observation for cross section of the specimens by optical microscope and SEM were conducted. In addition, mechanical properties of some specimens were evaluated by three-point bending tests using test pieces of $15 \times 50 \times 0.5 \mathrm{~mm}$ (thickness), $5 \mathrm{~mm}$ of bend radius, $2 \mathrm{~mm} / \mathrm{min}$ of pressing velocity and $22.5 \mathrm{~mm}$ of span between two support points. Bending strength was calculated from the maximum load reached before the test piece was fractured.

\section{Results and Discussion}

\section{3-1.Effect of sintering temperature on porosity and bending strength}

Fig. 3 shows the porous Ti sheet obtained by sintering powder A at $900{ }^{\circ} \mathrm{C}$ for $1 \mathrm{~h}$. Fully flat sheet was obtained and SEM image for the surface was quite similar to that for unsintered powders shown in Fig.2. Although powders are joined by diffusion bonding during sintering at $900{ }^{\circ} \mathrm{C}$ for $1 \mathrm{~h}$, characteristic feature of polyhedron shape of $\mathrm{HDH}$ powder remained unchanged. 

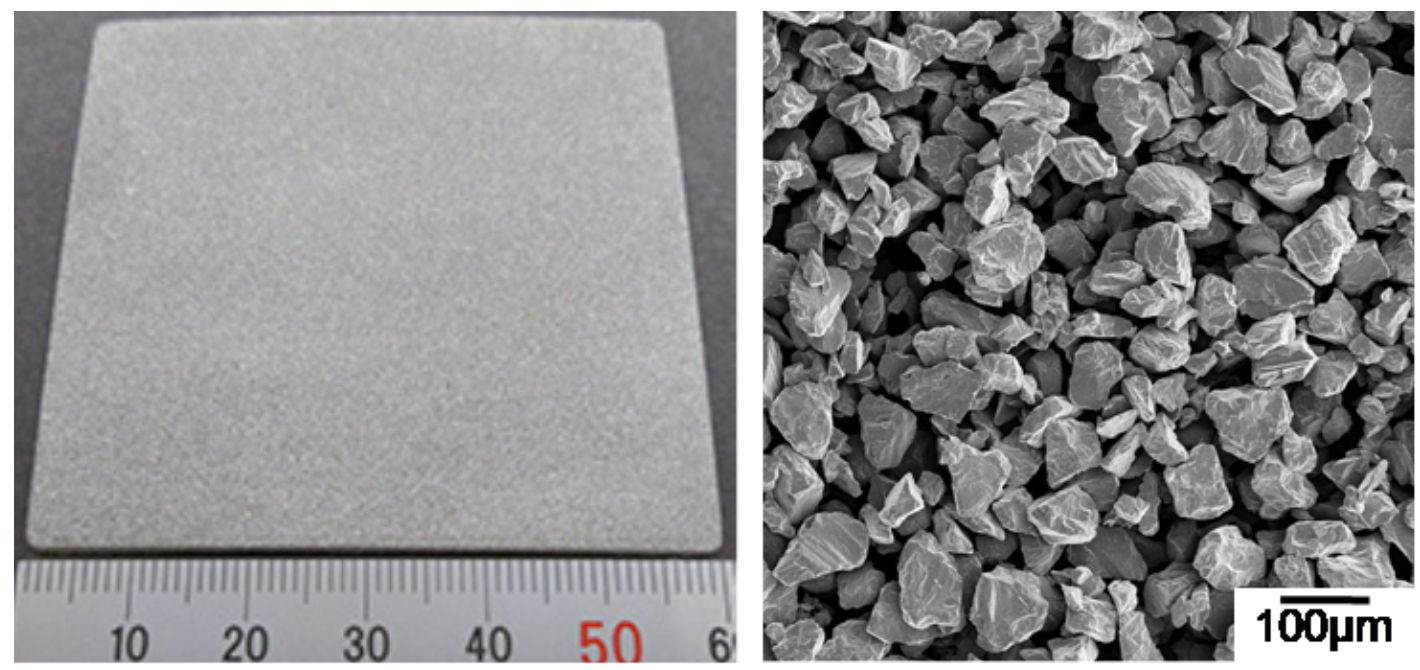

Fig.3 Appearance and SEM image of surface of porous Ti sheet of $0.5 \mathrm{~mm}$ in thickness, obtained by sintering powder $\mathrm{A}(45-150 \mu \mathrm{m})$ at $900{ }^{\circ} \mathrm{C}$ for $1 \mathrm{~h}$.

Fig.4 shows the relationship between sintering temperature and $\mathrm{O}$ concentration. O content slightly increased with increasing temperature although it was at most the level of ASTM Gr.2. As sintering was conducted in high vacuum, $\mathrm{O}$ content increase is considered to be caused by dissolution of passive oxide film on Ti powders, in which O diffused into Ti and solid solution $\mathrm{O}$ content is increased. This phenomenon is considered to be active at higher temperature, which is a reason why $\mathrm{O}$ content was high at high sintering temperature. It should be noted that after exposed in air after sintering, passive film forms again on the surfaces of porous Ti, and total $\mathrm{O}$ content increases to higher level compared to that of unsintered HDH powders $(0.11$ mass \%).

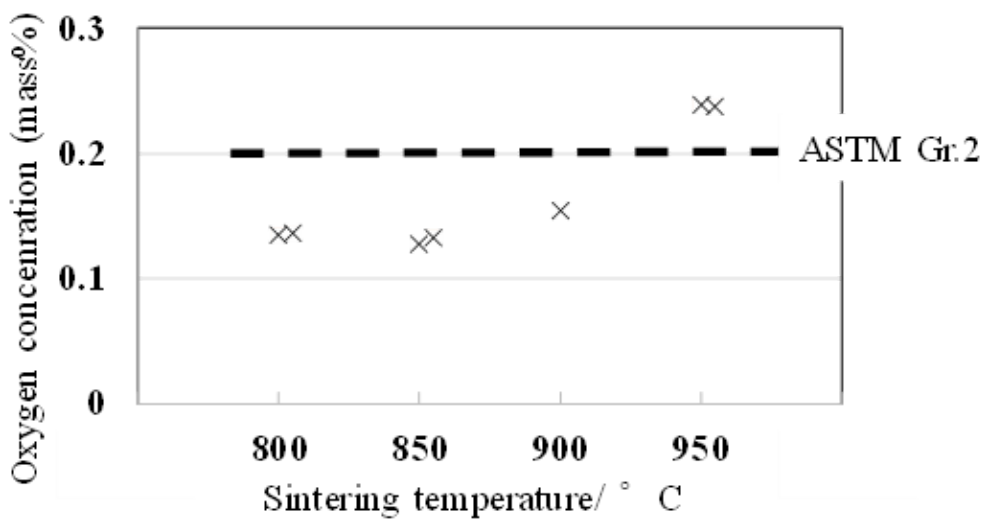

Fig.4 Relationship between $O$ content and sintering temperature in porous Ti sheet manufactured using powder $\mathrm{A}(45-150 \mu \mathrm{m})$. Sintering time was $1 \mathrm{~h}$. 
Fig. 5 shows effect of sintering temperature on density ratio and bending strength. Density ratio was not changed by sintering temperature and showed constant value between 38 to $42 \%$ regardless of sintering temperature. It is noticed that this density ratio is close to filling density of powder A, indicating that sintering effect is so slight that density was not changed from the initial state. On the other hand, bending strength greatly increased with increasing sintering temperature.

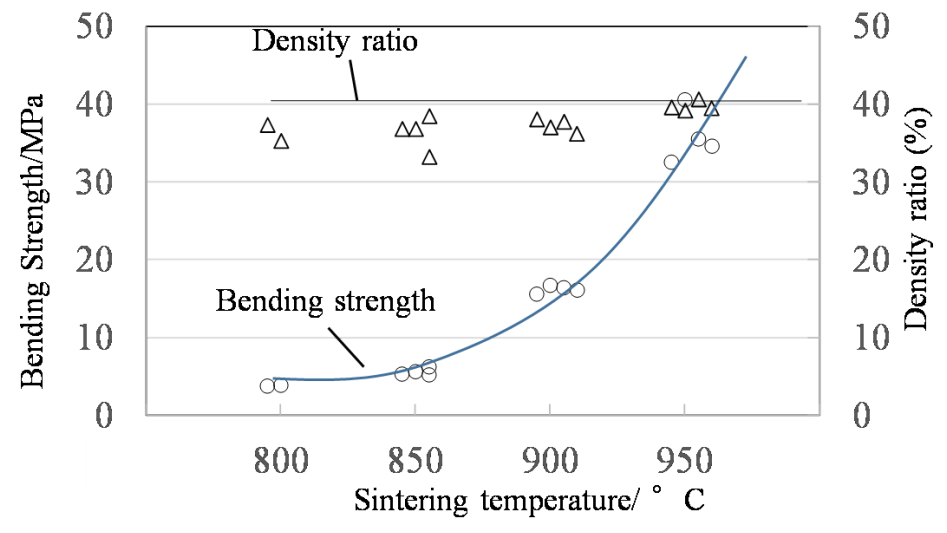

Fig.5 Effect of sintering temperature on density ratio and bending strength in porous Ti sheet manufactured using powder A (45-150 $\mu \mathrm{m})$. Sintering time was $1 \mathrm{~h}$.

Optical microstructures of cross sections of the porous Ti sheets manufactured using powder A are shown in Fig.6. Fig.6 (a) is for the specimen sintered at $850^{\circ} \mathrm{C}$ for $1 \mathrm{~h}$ and Fig. 6 (b) is for that sintered at $950{ }^{\circ} \mathrm{C}$ for $1 \mathrm{~h}$. Both had the same density ratio although bending strength was considerably different as shown in Fig.5. As can be seen in Fig.6(a), each powder in the specimen sintered at 850 ${ }^{\circ} \mathrm{C}$ had sharp corners, which is one of the characteristics of $\mathrm{HDH}$ powders, and portions touching adjacent powders were narrow as indicated by circles. Meanwhile, each powder in the specimen sintered at $950{ }^{\circ} \mathrm{C}$ had round corners, and portions touching adjacent powders were broad as indicated by circles (Fig.6 (b)). Those observations suggest that sintering progressed at high sintering temperature, but it was limited to the portions where adjacent powders contacted with each other. Firm bonding at the contacted portions contributed to high bending strength while sintering at the limited and localized portions contributed to high porosity without significant increase of density. As a result, good combination of porosity and mechanical properties was attained by sintering at $950{ }^{\circ} \mathrm{C}$ for $1 \mathrm{~h}$ with using powder $\mathrm{A}$, which had polyhedron shape suitable for the balanced properties in porous Ti sheet. 

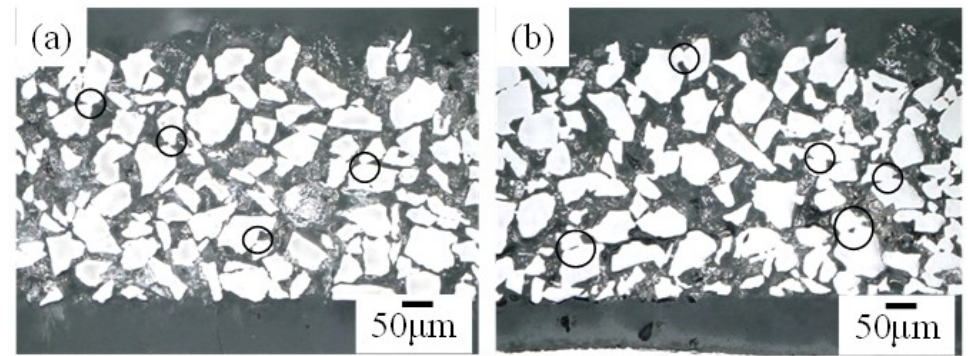

Fig.6 Optical microstructures of cross sections of porous Ti sheets manufactured using powder $\mathrm{A}(45-150 \mu \mathrm{m})$. (a) Sintered at $850{ }^{\circ} \mathrm{C}$ for $1 \mathrm{~h}$ (density ratio ; $42.1 \%$ ) and (b) sintered at $950{ }^{\circ} \mathrm{C}$ for $1 \mathrm{~h}$ (density ratio ; $41.5 \%$ ). Circles indicate some examples of portion contacting with adjacent powders.

Based on the knowledge obtained in the study, large sized porous titanium sheet of $0.5 \mathrm{~mm}$ in thickness was successfully manufactured by simple powder filling and sintering route, as shown in Fig.7.

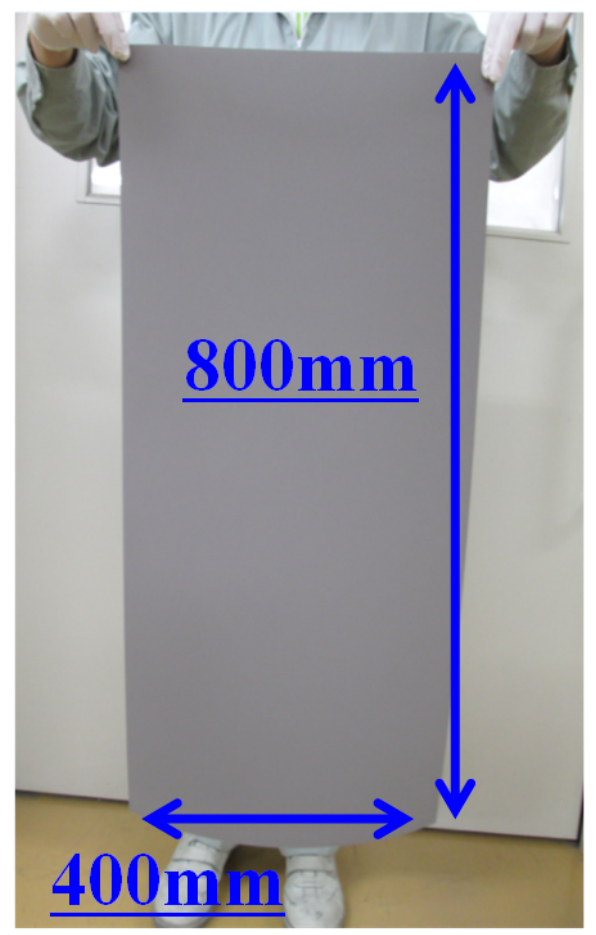

Fig.7 Appearance of large sized porous titanium sheet manufactured using Powder A (45-150 $\mu \mathrm{m})$. 


\section{3-2.Effect of addition of small size powders on porosity and bending strength}

Fig. 8 shows effect of sintering temperature on density ratio and bending strength of porous Ti sheet manufactured using powder A and powder B. The results for powder A is the same as that shown in Fig.5. Density ratio was slightly increased at lower sintering temperature. However, bending strength was not improved. Optical microstructures of the specimens exhibiting higher porosity and unimproved bending strength are shown in Fig.9. Small Ti powders were not distributed homogeneously and they were aggregated in some areas. Small powders contributes to higher density in general. However, they also make O content increased and they have a tendency to be segregated or to make bridges during powder filling. It is considered that due to the inhomogeneity caused by the inclusion of small powders of 10 to $45 \mu \mathrm{m}$, bending strength was not improved in spite of higher density.

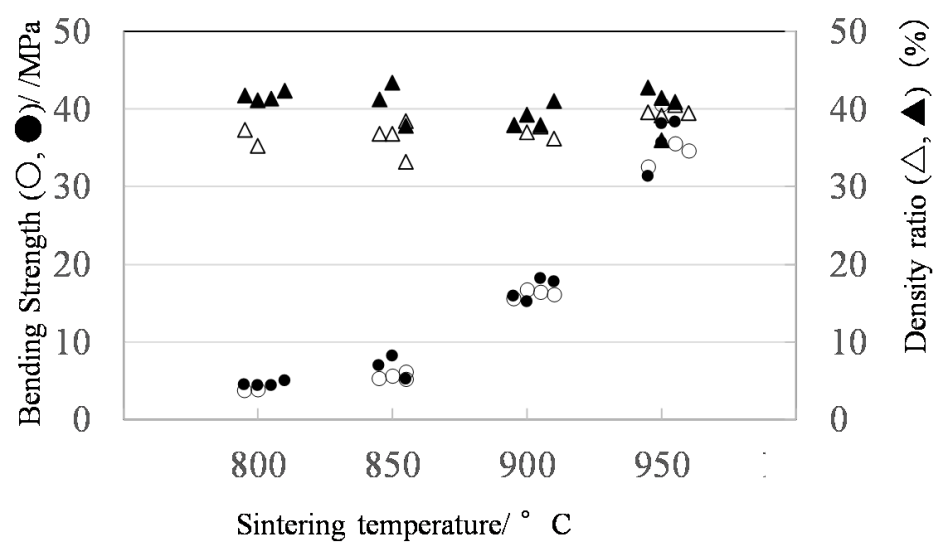

Fig.8 Effect of sintering temperature on density ratio $(\Delta, \Delta)$ and bending strength $(\circ, \bullet)$ in porous Ti sheet manufactured using powder A $(45-$ $150 \mu \mathrm{m})(\Delta, \circ)$ and powder $\mathrm{B}(10-150 \mu \mathrm{m})(\Delta, \bullet)$. Sintering time was $1 \mathrm{~h}$.

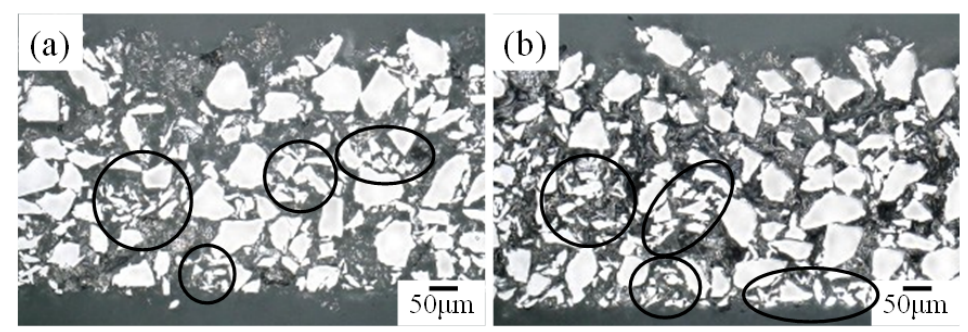

Fig.9 Optical microstructures of cross sections of porous Ti sheets manufactured using powder $\mathrm{B}(10-150 \mu \mathrm{m})$. (a) $\mathrm{Sintered} \mathrm{at} 800{ }^{\circ} \mathrm{C}$ for $1 \mathrm{~h}$ (density ratio ; $41.5 \%$ ) and (b) sintered at $850{ }^{\circ} \mathrm{C}$ for $1 \mathrm{~h}$ (density ratio ; $42.1 \%$ ). Circles indicate some examples of the area in which small powders were aggregated.

\section{Conclusion}


Effects of sintering conditions and grain size on porosity and mechanical properties in porous Ti sheet manufactured with simple sintering of loosely spread HDH Ti powders. Obtained results are as follows :

(1)The optimum sintering condition was $900-950{ }^{\circ} \mathrm{C}$ for $1 \mathrm{~h}$ to obtain porous Ti sheet with the balanced density ratio (around $40 \%$ ) and good mechanical property.

(2)The polyhedron shape of HDH powders contributed to those balanced properties of porous Ti sheet, in which localized sintering raised bending strength with keeping high porosity (low density).

(3)Some attention has to be paid when fine Ti powders are added.

(4)Using the optimum manufacturing conditions, large sized porous Ti sheet of $400 \times 800 \times 0.5 \mathrm{~mm}$ was successfully manufactured.

\section{Reference}

1. L. Z. Feng, W. Chen, C. Gang, T. Ping, Z. S. Yang, G. Yuan and Y. J. Gou : Key Eng. Mater., 770, p126-131(2018)

2. W. Prananingrum, Y. Tomotake, Y. Naito, J. Bae, K. Sekine, K. Hamada and T. Ichikawa : J. Mech. Behav. Biomedical Mater., 61 p581-589 (2016)

3. https://www.toho-titanium.co.jp/en/products/webtihp.html 